anomalous type in association with a secondary form of microtropia, because this provides an excellent cosmetic correction of the squint and a perfectly reasonable form of binocular association.

It is common to find some degree of amblyopia in a primary microtropic so that occlusion of the master eye is of value, but it is also essential to correct any underlying anisometropia by spectacle lenses or sometimes by contact lenses.-I amb etc.,

KENNETH WYBAR Moorfields Eye Hospital,
London E.C.1. and
Hospital for Sick Children,
Great Ormond Street,
London W.C.1

SIR,-I read with interest your leading article (17 August, p. 430) on this subject. Though you have obviously aimed at simplifying the subject as much as possible there are certain statements in it with which I would seek to disagree.

For instance, the following statement: "The management of most paralytic squints is straightforward, since they tend to derive in older patients from evident intracranial damage and gradually recover when the latter is rectified. They rarely require more than symtomatic relief of the attendant diplopia; this can be provided by advice on turning the head or by an ocluder on the spectacle lens." This is far removed from well-known facts, especially when one considers the large number of paralytic squints caused by head injury due to road accidents and the frequency of such squints in dysthyroid disease and in many other medical and neurological disorders. Bilateral fourth nerve and sixth nerve palsies often require quite complicated muscle operations and certainly nobody could regard the treatment of a third nerve palsy as simple and "straightforward," especially when one is dealing with patients of the younger or middle-aged groups.

The statement that in concomitant squints "except in congenital cases operation is usually deferred until the age of about 5 , by which time the child can also collaborate in orthoptic exercises" is not in line with current practice if the restoration of useful binocularity is envisaged.

Again, amblyopia (lazy eye) may not be a hopeless condition to treat even if the child is considerably over 10 years of age.

It is a pity that a leading article in your journal is not more up to date. It might have been written way back in 1938.-I am, etc.

London $W .1$

T. KEITH LYLE

** It is true that in cases of paralytic squint where recovery is incomplete and eyemuscle surgery is required the latter may entail expert handling. But the fair majority of paralytic squints do not call for ocular surgery and, as stated, the primary management is simply that of allaying the diplopia while the underlying cause of the paralysis is attended to.

As we stated, the treatment of amblyopia after the age of 10 is "rarely" suocessful. Mr. Lyle says that "amblyopia . . . may not be a hopeless condition" in the over-10 age roups. Agreed: but it usually is.

The figures for the last 200 cases at the branch of Moorfields at which Mr. Lyle worked show that the age of 5 was the commonest age at which concomitant squints underwent surgery and the ages of 6 and 2 were the runners-up (the 2-yearolds doubtless including many congenital cases). As he says, there is a tendency to operate at an earlier age, but our statement that "except in congenital cases operation is usually deferred until the age of about 5 " is evidently still correct.-ED, B.M.F.

\section{Glamourizing the Consultant}

SIR,-I feel that some comment must be made concerning B.B.C.2's "Philpott File" on 24 September regarding the National Health Service with particular reference to consultants. It seems very wrong to present to the public a glamourized view of medicine as practised in this country at present. Consultants do represent a reasonable percentage of medical staff, but certainly they do not all work in the conditions represented in this programme or indeed deal with the problems portrayed. Hence one might suggest that the total view represented was misleading.

For example, the first two items dealt with complex heart valve surgery and artificial kidneys, and renal transplantation. Even the most cynical medical man must have admired the technical skill and dedication of the medical workers, but surely we must stress that this represents a tiny proportion of "real" medicine as practised in this country within N.H.S. hospitals.

Casting aside one's irritation with this glamourized approach to hospital medicine, one was relieved to see the beginning of a presentation in the third part of the programme about a significant problem of medicine today-the care of elderly patients. However, any enthusiasm for this portion of the programme was soon dispelled by the observation of the enormous amount of staff involved in the care of these extremely privileged elderly patients in a hospital hardly representative of most other hospitals in this country. Small numbers of elderly patients were surrounded by a host of medical staff-indeed, surpassing the hordes of technical skill seen with the heart and kidney patients. There must be many of us in teaching hospitals outside London who would be embarrassed to be surrounded by so many physiotherapists and ancillary staff. How must our colleagues in non-teaching hospitals outside London, and especially in the north, feel at their total lack of any facilities in this direction when faced with a far bigger load of elderly patients?

In my opinion this programme was harmful in persuading the general population that the care of their health, whether it be in dramatic circumstances of severe heart or kidney disease or in the chronic process of ageing, is in the hands of many dedicated and skilled personnel. In reality the heart and kidney surgery will indeed in many instances be well catered for, but certainly the elderly problem will be understaffed, underfinanced, and practised in surroundings more fitted for the care of less attractive farm animals. Surely this programme to the realist must indicate the ungent need for a complete reassessment of medical needs and priorities.-I am, etc.,

J. D. WARD

Royal Infirmary,

Sheffield

\section{Experts and Child Abuse}

SIR,-While having complete sympathy with the general reaction to the Maria Colwell case and having personal experience of other children dying in very similar circumstances, I am disturbed lest, in the anxiety to prevent further similar tragedies, we may set up committees of experts in child abuse in each locality, as endorsed by your leading article (14 September, p. 641), and then feel that we have done all that is necessary.

Those of us who have been concerned with infant morbidity and death for many years are, as Dr. Selwyn M. Smith and Mrs. Ruth Hanson (p. 666) point out, aware that the background which produces the battered baby can also produce children showing no evidence of physical violence and who present as cot deaths. While the truly unexplained cot death of an apparently completely healthy baby does exist such cases are, in our experience, extremely rare. Much more common are those in which the principal factors leading to death are those of omission, and this is as important to these cases as the physical trauma is to the battered baby. This type of negative abuse cccurring in our community is, in my experience, very much more common than that of the battered baby.

During a prospective study of normal children and children at possible increased risk of unexpected death two things have become apparent. Firstly, that a prospective study of parents and children at increased risk of child neglect and abuse is a practical one. Secondly, the belief that the mechanisms as suggested by your leading article seem likely to lead to a vast amount of conferencing but little action.

In general, committees require too much evidence before taking action. Also if, as I suspect is true and as Pringle ${ }^{1}$ suggests, up to $18 \%$ of infants are subjected to some type of deprivation the numbers are so great that the only cases handled by a child abuse committee would be the rare, chronic, overt cases. It would seem to be much more practical to devise a soheme whereby health visitors can have their attention drawn to children likely to be at an increased risk of abuse and neglect long before there has been any complaint or notification of possible abuse and that these health visitors should have immediate access to an alerted casualty service where a community-oriented paediatrician can immediately take control and responsibility for the child. The identification of such children in the perinatal period is not impossible and I was disappointed to read the sentence in Dr. Smith and Mrs. Hanson's excellent article where they say, "We cannot predict which individual child will be battered." I understand that Kempe, for one at least, will not aocept this situation and I hope that Dr. Smith and Mrs. Hanson will seriously consider extending their study and attempt to apply some scoring criteria for identifying children at risk such as Carpenter ${ }^{2}$ has devised for our own study of possible unexpected deaths. 
To wait to see the effects of referral committees may result in many unnecessary deaths. - I am, etc.,

JOHN EMERY

Department of Histopathology, Children's Hospital,

\section{Sheffield}

Pringle, M. K., Proceedings of the Royal Society

of Medicine. In press.
Carpenter, R. G., and Emery, J. L., Nature, 1974,
250, 729 .

SIR,-The Brighton committee of inquiry into the death of Maria Colwell, keeping to its brief, has formulated an excellent report which pinpoints deficiencies in the coordination of agencies; but examination of the evidence shows that the lack of coordination was a subsidiary cause of the tragedy. The crucial decision to remove the child from her affectionate foster-parents did not call for co-ordination between the agencies, nor did the decision by the court to support the return of the child to her natural parents. The second crucial decision, to leave the child in a situation of hazard, arose from the misinterpretation of abundan immediate data. Co-ordinating the information of other agencies was irrevelant. A number of agencies had supporting evidence, but the unavailability of this evidence did not prevent neighbours coming to the right conclusions. Society, as your leading article (14 September, p. 641) states, did no fail, but the experts did. Using the public the system, and the lack of co-ordination of agencies as scapegoats will not deceive informed op:nion. We must look elsewhere than to lack of co-ordination of agenoies for the cause of the tragedy. It lay in matters unhappily outside the terms of reference of the inguiry-in the theoretical viewpoints that guided decision making.

The main wrong viewpoints were: that the natural parents are, in all ciroumstances, more adequate than other parents; that children should be returned to natural parents at the first opportunity; that fosterparents cannot supply totally satisfactory substitute care; that separation of children from parents is to be avoided at all costs. A monopolistic State machinery that maintains these viewpoints deliberately places large numbers of children at hazard in their own homes. This prescription for the management of child care produces an iatrogenic disorder.

The prescription for change must include the following.

(1) Changes of viewpoints about the essentials of child care which need to be taught to the relevant professions. The Brighton minority report gives an embarrassing picture of the bizarre, fanciful shibboleths rife in training schools.

(2) A national inquiry with wide terms of reference into ahild care procedures. Each death by battering (three more were reported in the Daily Telegraph on 17 September) deserves a local inquiry, but a national inquiry could have wider terms of referenoe.

(3) The provision of a specialist socia worker in child care, responsible for the supervision of children, for maintaining a confidential list of vulnerable children, and for collaboration with other professionals. Team work is admirable but secondary to careful evaluations of the family situation. Team responsibility should not replace in- dividual responsibility. The trust of families can be retained only with confidentiality.

(4) Any child admitted to hospital and suspected of being a victim of abuse should be referred to a psychiatrist, as is now the practice with attempted suicide. The psychiatrist would then undertake extensive family exploration and would collaborate with the medical man in continuous medical responsibility and with a social worker in continuous welfare responsibility for families.

(5) Area teams should consider children's services only broadly, as they are too slow and indecisive to be concerned in day-today case management and out across the essential requirement of individual responsibility.

(6) The legal position of children should be strengthened. Foster-parents should be represented in courts as a right. A "children's advocate" is likely to represent established expert opinion and would not have saved Maria Colwell. Better to put our faith in detached, careful magistrates, who are usually more in touch with common sense and public opinion. Courts can seek the opinion of a child psychiatrist when a detailed exploration of family pathology is required.

(7) Ohildren's voluntary societies should be strengthened to the point of being effective innovators and a realistic alternative to the state care of our children.-I am, etc.

Institute of Family Psychiatry,

J. G. Howells Ipswich

Report of the Committee of Inquiry into the
Care and Supervision Provided in Relation to Maria Colwell. London, H.M.S.O., 1974.

\section{Reporting Deaths to the Coroner}

SIR,-I am grateful to Dr. C. F. J. Baron (21 September, p. 740) for drawing attention to the opinion obtained by the B.M.A. in 1942.1 That opinion was based on the statement of the law which appeared in the contemporary edition of fervis on Coroners, for which counsel claimed there was "plenty of judicial authority." As he gave no references to these we are thrown back on references given in the edition of Jervis from which he quoted, but these are al concerned with the indictable misdemeanour of obstruction of the coroner and not with any common-law duty.

Having given no more authority for the existence of a common-law duty than a reference to Jervis, counsel argued that "unless a statutory provision can be found which expressly, not implicitly, overrides this particular duty, the duty is still binding on a medical practitioner." Counsel also claimed that "until the passing of the Births and Deaths Registration Act, 1926, no medical man seems to have questioned his obligation to report to the coroner any death into which the coroner ought to inquire." This suggests that counsel was unaware of the repeated references to the controversy which had appeared before 1926 in medical journals and that he was also unaware of its frequent mention in parliamentary papers before that date, including the reports of select committees, departmental committees, and Bills, some of which attempted to resolve the issue by placing a statutory duty on doctors to notify the coroner.

It is hardly surprising that the 1943 opinion from Sir Roland Burrows was so decisive and that subsequent editions of Jervis have stated the law correctly-that is, there is no duty enforceable at common law on a doctor (or any other person "about the deceased") to notify the coroner of deaths coming within his jurisdiction.

Dr. Baron claims that "in the absence of a judicial decision, there must be room for more than one view." It is difficult to see why he should prefer an opinion which is based on a false assumption that judicial decisions do exist.-I am, etc.,

Harpenden, Herts

J. D. J. HAVARD

British Medical fournal Supplement, 1942, 2, 25. fervis on the Office and Duties of Coroners, ed. Sweet and Maxwell, 1927.

\section{Dangers of Oxytocin-induced Labour to} Fetuses

SIR,-Messirs. W. A. Liston and A. J Campbell (7 September, p. 606) were wise to draw attention to the very real risks to the fetus associated with the injudicious use of oxytocin, but the conclusions drawn from their retrospective study are not supported by their results. No significant difference was demonstrated between the frequencies of fetal distress, low Apgar scores, or admission of babies to the special nursery when high or low doses of oxytocin were used during labour. No other valid comparison could be made because of the differences between the groups of patients studied. It is probable that a large proportion of abnormal pregnancies and labours were included within the group of oxytocinstimulated labours, which biased the results towards a greater incidence of neonatal asphyxia in this group. The only conclusion which might reasonably be drawn from these results is that the dose of oxytocin used to "stimulate" labour did not appear to influence the condition of the neonate at birth when judged by the parameters chosen.

This observation is supported by the results of my own previously unpublished prospective series of 510 patients in which labour was induced artificially by amniotomy and simultaneous intravenous oxytocin. All were between 38 and 42 weeks pregnant with a cephalically presenting fetus and were more than $152 \mathrm{~cm}$ tall. This degree of selection was necessitated by the main purpose of the investigation, which was totally unrelated to the study of fetal wellbeing, but no selection was made for age, parity, abnormality of pregnancy, or indication for induction. The patients were divided into two groups, those in the first receiving oxytocin in low doses (maximum 16. $\mathrm{mU} / \mathrm{min}$ ) regardless of uterine activity while in the second group oxytocin was titrated in rapidly increasing doses against the amount of uterine activity. A fetus was considered to be asphyxiated if an Apgar score of less than six was recorded either at one or 10 minutes after birth. Low doses of oxytocin were used to induce 200 labours, and $11(5.5 \%)$ of the neonates had low Apgar scores. Titrated oxytocin was employed in 310 patients with the result that $23(7.4 \%)$ of the neonates had low Apgar 